\title{
Medical Internal Radiation Dose
}

National Cancer Institute

\section{Source}

National Cancer Institute. Medical Internal Radiation Dose. NCI Thesaurus. Code C95159.

The absorbed dose for a subject that results from ingestion of sources of radiation that reside throug hout the subject over time. In particular a well-defined MIRD system of calculating this dose for radiopharmaceuticals in humans from properties of the subject and its internal sources has been developed and maintained by the Society of Nuclear Medicine. 